Revista Mídia e Cotidiano

Editorial

Volume 11, Número 3, dezembro de 2017

\title{
RETÓRICA DOS ESTEREÓTIPOS, PRÁTICAS DISCURSIVAS E PERFORMANCES CONTEMPORANEAS
}

\section{THE RHETORIC OF STEREOTPYPES, DISCURSIVE PRACTICES AND CONTEMPORARY PERFORMANCES}

\author{
Bruno DEUSDARÁ ${ }^{1}$ e Guilherme Nery ATEM ${ }^{2}$
}

Em uma rápida e intensa alteração das configurações do debate público na cena republicana brasileira, temos observado a emergência insistente e reiterada da atualização de estereótipos e imagens cristalizadas tradicionais excludentes que ora se reforçam, ora se inscrevem em performances de combate. Esse redimensionamento, que se realiza pela intensidade de traços conservadores e excludentes, parece apropriar-se de modo singular das práticas discursivo-midiáticas, necessitando ser mais bem entendido, a partir de uma torção da compreensão a respeito da trajetória recente de consolidação das lutas por direitos empreendidas pelas chamadas minorias. Se essa torção se caracteriza, como aponta Rancière, pelo pretenso "combate à inflação dos direitos sociais", fica evidente seu vetor autoritário e restritivo.

Ao lado de estudos críticos acerca da emergência dessas figuras cristalizadas e estereotípicas, que dão sustentação aos conservadorismos e às exclusões, consideramos necessária a reflexão sobre materiais que evidenciem o exercício de práticas discursivas e performances contemporâneas, propondo alternativas às segmentações duras e às cristalizações provenientes dos estereótipos. Assumindo o desafio de interrogar essas imagens cristalizadas na composição dos processos contemporâneos, os artigos que compõem este dossiê fornecem chaves interpretativas interessantes e atuais, a partir de

\footnotetext{
${ }^{1}$ Professor do PPG em Letras e da graduação em Letras (ILE-UERJ e FFP-UERJ). Doutor em Psicologia Social (UERJ) e Pós-Doutorando em Mídia e Cotidiano (UFF).

${ }^{2}$ Professor do PPG em Mídia e Cotidiano e da graduação em Comunicação Social (UFF). Doutor em Comunicação e Cultura (UFRJ) e Pós-Doutor em Letras (UERJ). Líder do grupo de pesquisa "ReC: Retórica do Consumo".
} 
diálogos com referenciais teórico-conceituais oriundos de diferentes campos disciplinares, para investigar a construção midiática de algumas das principais questões da atualidade.

No artigo intitulado "Imagens cristalizadas: a construção de estereótipos sobre favelas", Daniella Guedes Rocha investiga as representações midiáticas sobre favelas e seus efeitos na configuração das imagens de seus moradores. A autora recupera as reflexões críticas de Zaluar e Alvito (2006) a respeito de representações que remontam ao início do século XX e de Manso (2002), as quais indicam que os pobres moradores de favelas, vítimas constantes da violência, são apontados como seus agentes. Daniella Rocha parte de um enquadramento histórico e o aplica a matérias atuais. Nas análises realizadas, destacam-se os sentidos que reforçam a favela como espaço de criminalidade e, secundariamente, também se destaca a perspectiva da "ausência". De acordo com a autora, a referência à favela como espaço do trabalhador é bem mais restrita.

Em “A circulação de representações sociais de favelas do rio de Janeiro no discurso fotojornalístico", Janaína Barcelos estuda representações sociais que vinculam o espaço da favela e seus moradores aos processos de marginalização e violência. Com o referencial teórico fundamentado em conceitos como representação social, estereótipos e imaginários sociodiscursivos, a autora investiga a construção de sentidos sobre a favela em seus moradores. Como material submetido à análise, a autora opta pelo trabalho com fotos jornalísticas/documentais. No artigo, a autora menciona o histórico de políticas públicas de orientação higienista e um reconhecimento tardio das favelas pelo poder público, nos anos 30. Em contrapartida a esse histórico, a autora apresenta estudos que enfatizam a atuação crítica dos movimentos sociais, promovendo alterações nessas representações. Em suas análises, ressaltam-se aspectos como a desigualdade na distribuição geográfica das favelas representadas, a reiteração de certos temas, entre outros aspectos. Na comparação com imagens presentes em outro material, novos sentidos emergem, apontando para aspectos da vida popular nas favelas e sua relação com as políticas de segurança pública.

Em "Juventude, tecnologia e inovação: uma construção mítica na contemporaneidade", Bruno Pompeu e Silvio Koiti Sato abordam os processos que 
conduzem a uma hipervalorização da juventude como efeito dos processos contemporâneos da cultura do consumismo. Para tanto, os autores conduzem abordagem crítica da tecnologia e sua valorização da transitoriedade e da efemeridade. Tais elementos mantêm articulação, de acordo com o debate desenvolvido pelo artigo, com processos que estão na base da construção da juventude como mito. Em suas análises, os autores investigam anúncios publicitários construídos a partir de representações da juventude. Na perspectiva crítica desenvolvida, traços como positividade e afetividade, atribuídos à juventude, emergem como uma pretensa alternativa aos tempos de insegurança e fragilidade.

Em "Tradição e modernidade: música caipira e sertaneja na editoria de música da revista Veja", Fernando Lopes e Karina Janz Woitowicz problematizam as tensões na representação da música caipira, ressaltando seu processo de urbanização, a partir dos anos 70. Percorrendo referências de base na investigação desse fenômeno, os autores apresentam um panorama relevante a respeito da temática, que contribui com a sustentação das análises que realizam. Para as análises, os autores demonstram, por meio de dados diversos acerca da distribuição de temáticas, estilos e origem das modalidades musicais abordadas pela Veja, o lugar conferido à música caipira nesse universo de textos. Nas análises do material selecionado, os autores observam a recorrência de certas temáticas, bem como a emergência de uma crítica aos "empresários da música".

Em “O estereótipo da mulher no jornal 'Dez Minutos' de Manaus/AM”, Adriano Rodrigues, Rafael Lopes e Gilson Monteiro investigam de que modo se realiza a exploração da imagem de corpos femininos como recurso editorial, no chamado “jornalismo sensacionalista". Em sua investigação, os autores analisam o emprego de imagens femininas em capas de um jornal com circulação no estado do Amazonas. Como referencial teórico, os autores articulam uma perspectiva semiótica com a teoria corpomídia. Para fundamentar suas análises, os autores discutem, com base em conceitos da semiótica, a importância da capa no funcionamento do jornalismo impresso. Tal discussão terá, no artigo, desdobramentos relativos às tensões entre estética, ética e relações econômicas, que contribuem com as análises das imagens, ressaltando as convergências entre cultura do machismo e sua exploração pela cultura do consumismo. 
Já em "Valorização da diversidade ou apenas publicidade? Uma análise de conteúdo de campanhas da Natura”, Maria Amélia Paiva Abrão e Maria Cristina Dias Alves apresentam, no título do artigo, a questão que orienta suas análises. Desse modo, as autoras discutem de que modo a publicidade se apropria da diversidade, favorecendo ou não a emergência de novos sentidos. Para as análises propostas, as autoras articulam os instrumentos da análise de conteúdo com a perspectiva teórica de E. Goffman, procurando observar os sentidos que são reforçados nos anúncios em análise. No processo de investigação, as autoras recuperam estudos que discutem o lugar conferido à mulher em diferentes esferas da vida social e confrontam tais estudos com os dados oriundos de aspectos variados, observados nos anúncios. Os resultados alcançados demonstram a permanência de tensões e representações cristalizadas na imagem feminina, mesmo quando o projeto é explicitamente o de as criticar.

No artigo "Um dia compro apartamento e viro socialite: tipificação e estereótipo na telenovela Cheias de Charme", Tatiana Oliveira Siciliano e Licia Marta da Silva Pinto discutem as representações e os estereótipos presentes na construção da personagem "empregada doméstica", enfatizando as relações familiares e laborais. Para fundamentar sua discussão, as autoras abordam processos recentes acerca de conquistas trabalhistas das empregadas domésticas, incluindo, nessa discussão, aspectos relativos à configuração das relações étnicas e de gênero. As autoras procedem a levantamento acerca da construção das personagens, a partir das relações que estabelecem na trama. $\mathrm{Na}$ sequência, as autoras produzem análises a respeito da construção das personagens, baseadas em um denso referencial teórico em que se articulam conceitos da análise da narrativa, dos estudos da linguagem, da sociologia, dos estudos culturais, explorando as tensões e seus desdobramentos no âmbito da telenovela investigada.

Por fim, no artigo "Tipificando o atípico: a performance de gênero de Pabllo Vittar no Instagram", Ana Paula Costa, Lucas Bragança e Fábio Goveia partem de publicações feitas pela artista em sua rede social e propõem uma tipologia das imagens, bem como um mapeamento dos modos de engajamento dos internautas. Visando a uma compreensão aprofundada e complexa - como o fenômeno em questão requer - a respeito de como a artista justapõe os gêneros tradicionalmente binarizados, os autores buscam compreender 
e ressaltar como Pabllo Vittar expande e ressignifica as relações entre corpo, gênero e sexo. $\mathrm{O}$ artigo articula o contexto da cibercultura com o evidente potencial político - em termos de crítica à tradição e resistência aos estereótipos - da performance artística. Ao mesmo tempo: arte e política; expressão e conteúdo; práticas sociais e discursivas. Signos e ideologias. Mídia e Cotidiano.

Além dos artigos publicados no dossiê temático, a revista apresenta mais seis textos em sua seção livre. Os temas abordados incluem: as novas configurações tecnológicas trazidas pela convergência e presentes nas dinâmicas das TVs universitárias (artigo de Olga Tavares); a análise do smartphone como dispositivo de escuta, considerando-o como máquina sensorial de múltiplas funcionalidades, cuja relação com os usuários possui elementos de natureza técnica, estética e ideológica (artigo de Bruno Henrique Cremonez e Eduardo Nespoli); o papel que fotografias antigas de ambientes urbanos exercem na construção de memórias coletivas nas cidades (artigo de Letícia Cantarella Matheus e Rafaella Prata Rabello); a análise de desenhos produzidos por estudantes e a contribuições destes desenhos para a expressão de sensações dos lugares e para a compreensão do campo temático do território (artigo de Anna Paula Soares e Joaquim Humberto Coelho de Oliveira); as conexões entre as narrativas sobre uma "epidemia de crack", que circulam na imprensa, e o imaginário social brasileiro (artigo de Wilson Couto Borges e Igor Sacramento) e, por último; a discussão de um evento da cultura de jogos digitais onde mulheres, LGBTQs e pessoas não-brancas foram hostilizadas e agredidas e a relação dessa cultura com a identidade do "homem nerd" (artigo de Lucas Goulart e Henrique Nardi).

Esperamos que tenham uma ótima leitura e desejamos um ano novo de muitas realizações e conquistas. 